\title{
OPEN Genetic diversity and mate selection in a reintroduced population of gray wolves
}

\author{
David E. Ausband $(\mathbb{D}$
}

The genetic composition of an individual can markedly affect its survival, reproduction, and ultimately fitness. As some wildlife populations become smaller, conserving genetic diversity will be a conservation challenge. Many imperiled species are already supported through population augmentation efforts and we often do not know if or how genetic diversity is maintained in translocated species. As a case study for understanding the maintenance of genetic diversity in augmented populations, I wanted to know if genetic diversity (i.e., observed heterozygosity) remained high in a population of gray wolves in the Rocky Mountains of the U.S. $>20$ years after reintroduction. Additionally, I wanted to know if a potential mechanism for such diversity was individuals with below average genetic diversity choosing mates with above average diversity. I also asked whether there was a preference for mating with unrelated individuals. Finally, I hypothesized that mated pairs with above average heterozygosity would have increased survival of young. Ultimately, I found that females with below average heterozygosity did not choose mates with above average heterozygosity and wolves chose mates randomly with respect to genetic relatedness. Pup survival was not higher for mated pairs with above average heterozygosity in my models. The dominant variables predicting pup survival were harvest rate during their first year of life and years pairs were mated. Ultimately, genetic diversity was relatively unchanged $>20$ years after reintroduction. The mechanism for maintaining such diversity does not appear related to individuals preferentially choosing more genetically diverse mates. Inbreeding avoidance, however, appears to be at least one mechanism maintaining genetic diversity in this population.

The genetic composition of an individual can markedly affect its survival, reproduction, and ultimately fitness ${ }^{1}$. Because they are often coupled with conservation efforts, many studies have focused on species that are genetically impoverished (e.g., low individual heterozygosity ${ }^{2-4}$ ). From a wealth of such studies, we know that being genetically impoverished can lead to changes in mating behaviors (e.g., time spent mating ${ }^{5}$ ), reduced reproductive vital rates ${ }^{6}$, an inability to combat disease ${ }^{7}$, reduced survival, and increased probability of population extinction ${ }^{8}$. In contrast, having a diverse genetic composition can lead to increased fitness over a lifetime ${ }^{9}$. Indeed, correlations between individual heterozygosity and fitness (i.e., heterozygosity-fitness correlations) have been observed in several species ${ }^{1}$ although the overall strength of the effect has been questioned ${ }^{10,11}$. Selecting for genetically diverse mates is not the only path to enhanced diversity, however, individuals may also preferentially choose to mate with unrelated individuals (i.e., inbreeding avoidance) making loss of genetic diversity less likely over time.

For mammals, both sexes breed and the young they produce are diploid, receiving half of their DNA from each parent. Selection may favor individuals who, if genetically impoverished, choose to breed with more diverse partners so that their resulting young are more genetically diverse than the parents ${ }^{12}$. Indeed, studies have shown that individuals will choose mates with higher average heterozygosity than what is expected if there were random mating in the population ${ }^{13,14}$.

As many wildlife populations become smaller, fragmented, and isolated, conserving genetic diversity will be a conservation challenge. For example, many imperiled species are supported through population augmentation efforts such as captive breeding and translocations. Many augmentation efforts actively manage for genetic diversity ${ }^{15}$ although in some cases there are few remaining individuals and managers are limited by an inherent lack of remnant diversity ${ }^{16,17}$. Even when the best efforts are made and sufficiently diverse source populations remain, the ability of managers to maintain diversity in wild populations hinges on largely uncontrollable 


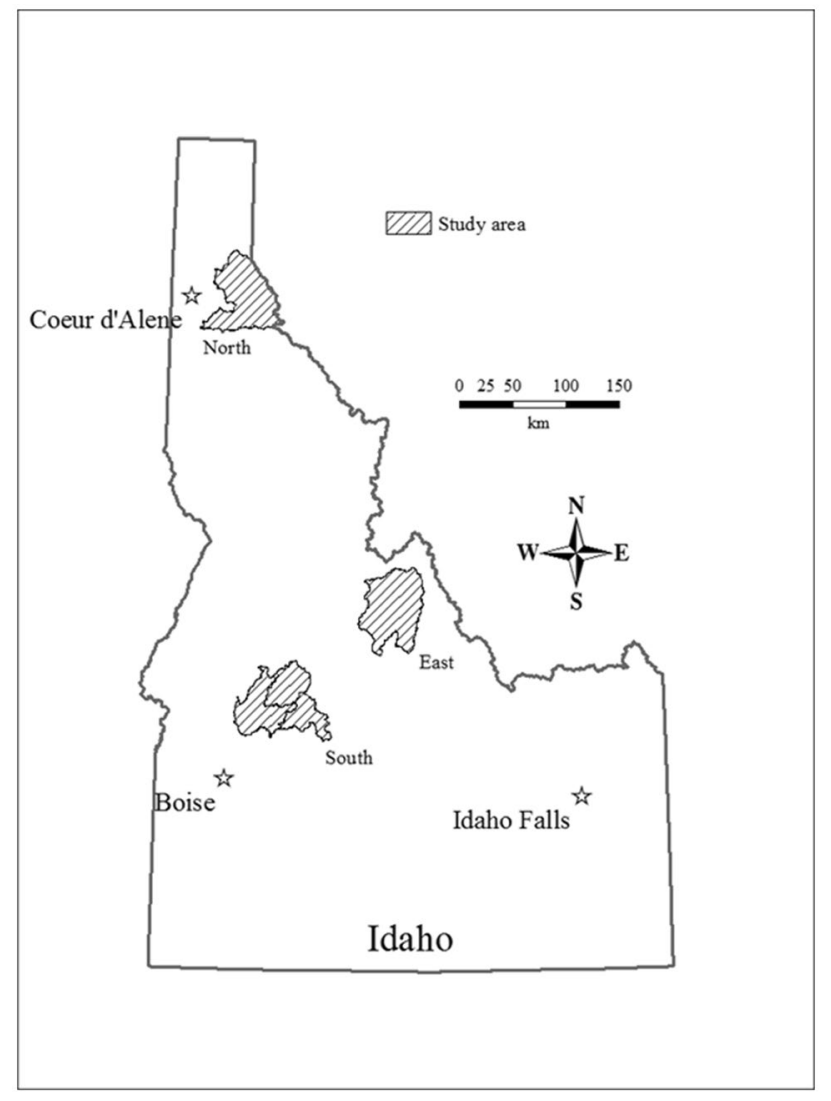

Figure 1. Study areas (i.e., subpopulations) in Idaho, USA, where wolves were genetically sampled, 2008-2017.

mate-selection choices made by resident or translocated individuals. We often do not know how genetic diversity is maintained in the wild after release for many translocated species.

Gray wolves (Canis lupus) were extirpated from the Rocky Mountains of the U.S. by the 1930s. A small $(n=35)$, genetically diverse (Observed heterozygosity, $\left.\mathrm{H}_{\mathrm{o}}=0.70^{18}\right)$ population of wolves was reintroduced to Idaho, USA, in 1995-1996 from nearby source populations in Alberta and British Columbia, Canada ${ }^{19}$. Wolves are generally considered quite fecund, but their social structure typically limits breeding to two individuals per group, thus the effective population size or number of breeding individuals is a small fraction of total population abundance. Although typically monogamous, wolf mating systems are flexible with polygyny, polyandry, and "sneaker" males observed in wild populations ${ }^{20}$. Rubenstein ${ }^{14}$ found such extrapair matings in some bird populations were a means to secure more genetically diverse offspring although this has yet to be explored in wolves.

I wanted to know if genetic diversity remained high in a population $>20$ years after reintroduction. Therefore, I evaluated (1) genetic diversity in a reintroduced population of gray wolves, (2) if genetic diversity was maintained in this population through individuals with below average genetic diversity choosing mates with above average genetic diversity, (3) if wolves showed inbreeding avoidance by mating with unrelated individuals, and (4) if mated pairs with above average heterozygosity had increased survival of young.

\section{Materials and methods}

Study areas. I sampled wolves in three study areas (north, east, and south) that included 5 Game Management Units (GMU's) within Idaho, USA (GMUs 4, 28, 33-35; Fig. 1). Each study area was embedded in the larger population of wolves that spanned most of Idaho and movement of wolves from one study area to another was rare due to distance (Fig. 1). All study areas were mountainous regions of primarily United States Forest Service (USFS) lands. During the years we sampled, annual temperatures ranged from $-13{ }^{\circ} \mathrm{C}$ to $36^{\circ} \mathrm{C}^{21}$. Annual precipitation ranged from 30 to $130 \mathrm{~cm}^{21}$. Elevation ranged from 646 to $3219 \mathrm{~m}$. The northern study area (GMU 4; $3189 \mathrm{~km}^{2}$ ) had a maritime climate dominated by western red cedar (Thuja plicata), Douglas fir (Pseudotsuga menziesii), Engelmann spruce (Picea engelmannii), and lodgepole pine (Pinus contorta). The eastern (GMU 28; $3388 \mathrm{~km}^{2}$ ) and southern (GMUs 33-35; $3861 \mathrm{~km}^{2}$ ) study areas had a continental climate and were dominated by ponderosa pine (P. ponderosa), lodgepole pine, spruce mixed forests, and sagebrush (Artemisia tridentata) steppe. Public harvest of wolves began in Idaho in 2009, temporarily ceased in 2010, and began again in 2011 and annually thereafter. Wolves were harvested using rifles $(65.7 \%)$, traps $(32.7 \%)$, and archery $(<2 \%)^{22}$. Most harvest occurred during September-March with a peak during the big-game rifle hunting season in OctoberNovember ${ }^{22}$. 
Field methods. From June to August 2008-2017, we collected wolf scats at occupied or recently occupied wolf pup-rearing sites. When available, we used GPS or radio-telemetry locations of wolves to locate pup-rearing sites. During 2008-2010 we used no radiocollar information to find wolves, from 2011 to 2014 approximately $65 \%$ of our study groups contained collared individuals although their locations did not always help us find pups. From 2015 to 2018, we again used no collar information. At sites of both collared and uncollared wolves, we surveyed historical pup-rearing sites and sites predicted by a habitat model to have a high probability $(\geq 70 \%$ suitability) of being a pup-rearing site ${ }^{23}$. At each predicted site, technicians attempted to find an activity center (area where pups congregate) through howl surveys ${ }^{24}$ or by searching the area around wolf GPS clusters and radio-telemetry locations. Once the activity center was located, $4-8$ technicians collected pup and adult scat for $3-5 \mathrm{~h}$, radiating out from the activity center up to $500 \mathrm{~m}$ to ensure a sufficient sample of adult scats ${ }^{23,25}$. Incidental scats found outside of pup-rearing sites were also collected. We collected 125-200 samples per group per year, which generally detected every individual in the group ${ }^{25}$. We attempted to resample each group $(n=16)$ in every study area every year.

Laboratory methods. DNA analyses were conducted at the University of Idaho's Laboratory for Ecological, Evolutionary and Conservation Genetics (Moscow, ID, USA). We extracted DNA from scats using Qiagen kits (DNA stool mini kit and DNeasy; Qiagen, Valencia, CA, USA) with a negative control to test for contamination. We first screened all samples in a species-identification test using co-amplification and fragment analysis of 3 short segments of the mitochondrial DNA control region to remove non-target species and lowquality samples ${ }^{26}$. We then attempted to genotype all samples identified during the mtDNA test as wolf or dog (C. familiaris) using 18 nuclear DNA microsatellite loci; (AHT103, AHT109, AHT121, AHT200, C05.377, C09.173, C37.172, Cxx.119, Cxx.250, FH2001, FH2004, FH2010, FH2054, FH2088, FH2137, FH2611, FH2670, $\mathrm{FH} 3725)^{27-31}$. We initially amplified all samples twice for genotyping and required successful amplification of alleles at $\geq 5$ loci for the sample to continue for an additional 1-3 PCRs, whereas we discarded samples that amplified at $<5$ loci. For each locus, we required $\geq 2$ independent PCR amplifications for consensus of a heterozygote and $\geq 3$ independent PCR amplifications for consensus of a homozygote. We compared all consensus genotypes (i.e., 18 loci) and all unique genotypes of previously identified individuals using Genalex $6.503^{32}$ to match samples and distinguish unique genotypes. To avoid overestimation and account for undetected genotyping errors, we grouped samples mismatching by allelic dropout at only 1 locus (e.g., 102, 0 vs. 102, 106) as a single individual $^{33}$. We used Reliotype ${ }^{34}$ to test the accuracy of unique genotypes represented by only 1 noninvasive sample (i.e., single detections) by ensuring the genotype attained a 95\% accuracy threshold. Further details regarding laboratory methods can be found $\mathrm{in}^{25,35-37}$.

In 2008 and 2009, we analyzed all collected samples. After 2010, we analyzed 40 adult and 25 pup samples from each group based on results of resampling and rarefaction ${ }^{35}$. If a group had more than two individuals detected only once we analyzed additional samples when available to obtain 10 more consensus genotypes. We compared genotypes from tissue samples of harvested wolves in fall/winter to genotypes of wolves detected in the previous summer by fecal DNA sampling to estimate an annual harvest rate (i.e., number detected in harvest/ number detected in summer).

\section{Analyses}

For each year I included all sampled adult males and females as potential parents and all sampled pups as potential offspring of every pair of individuals and then determined breeders and their offspring by constructing pedigrees using maximum-likelihood in program COLONY version 2.0.5.5 $5^{38}$. I first calculated allele frequencies for each year in program COANCESTRY version 1.0.1.5 $5^{39}$ and then imported the frequencies into program COLONY for use in pedigree analyses. I allowed for polygamy in both males and females and assumed an allelic dropout rate of 0.01 and genotyping error rate of 0.01 . In cases where parentage was undetermined from COLONY, I further examined offspring genotypes against the likely parents of the remaining offspring in the group and allowed for a two allele mismatch owing to allelic dropout between parent and offspring to verify parentage across the 18 loci using exclusion methods ${ }^{1}$. Once breeders were identified from pedigree analyses, I used Program Coancestry ${ }^{39}$ to estimate Trio ML genetic relatedness between the breeders. Lastly, I used Program STORM $^{40}$ to assess whether relatedness between observed breeding pairs was different if there were random mating in the population. To do this, I populated STORM with 151 potentially reproductive ( $\geq 2$ years old) male genotypes and 167 potential reproductive ( $\geq 2$ years old) female genotypes. I then simulated 151 mated pairs using sampling with replacement and estimated relatedness between simulated mated pairs over 10,000 iterations.

I sampled the same groups of wolves across consecutive years and from the resulting pedigrees determined the breeders, pups, paternity from sneaker males (i.e., males who sired pups but were unsampled and unaffiliated with any sampled pack), evidence of polygamy (i.e., more than one female in the group gave birth to pups), and duration (i.e., years) each breeding pair was bonded. I considered pair bond duration equal to 1 year at the first breeding event between two individuals. Sneaker male genotypes were reconstructed from mother and offspring genotypes using Program COLONY. Because I sampled wolves in early to mid-summer, pups were approximately 3 months old. I returned the following year to resample and determine whether they were alive or dead 15 months after birth (i.e., apparent survival). Fewer than $4 \%$ of wolves (approx. 1.1 pup/year total in the study areas) disperse within their first year in the study population ${ }^{41}$ thus I assumed absence at 15 months meant death. I further examined genotypes of harvested wolves throughout the state (250-350 wolves annually from mandatory check-in) to determine if pups dispersed early and were harvested. No early dispersal events were discovered this way. After extracting DNA from tissue of harvested wolves, I calculated annual harvest rate by dividing the number of genotypes detected in harvest in the study areas via tissue samples from mandatory 


\begin{tabular}{|l|c|l|l|}
\hline Covariate & \multicolumn{4}{l|}{$\boldsymbol{\beta}$} & SE & $\boldsymbol{P}$ \\
\hline Fixed effects model \\
\hline Intercept & 0.02 & & \\
\hline Harvest rate & -0.56 & 0.12 & $<0.0001$ \\
\hline No. adults & 0.19 & 0.12 & 0.11 \\
\hline Pair $\mathrm{H}_{\mathrm{o}}$ & -0.12 & 0.12 & 0.32 \\
\hline Population density & -0.18 & 0.12 & 0.13 \\
\hline Years paired & 0.28 & 0.13 & 0.04 \\
\hline Mixed effects model & & & \\
\hline Intercept & 0.02 & & \\
\hline Harvest rate & -0.61 & 0.14 & $<0.0001$ \\
\hline No. adults & 0.19 & 0.16 & 0.23 \\
\hline Pair Ho & -0.01 & 0.19 & 0.94 \\
\hline Population density & -0.13 & 0.15 & 0.38 \\
\hline Years paired & 0.26 & 0.19 & 0.17 \\
\hline RE (pair_ID) & $0.85(\mathrm{SD})$ & & \\
\hline
\end{tabular}

Table 1. Covariates from fixed and mixed effects models predicting wolf pup survival in Idaho, USA, 20082017. $H_{o}$ observed heterozygosity, $R E$ random effect.

harvest check-in by the number of genotypes detected the previous summer during field sampling. Finally, I used Program Genalex $6.503^{32}$ to calculate the observed heterozygosity of breeding individuals.

I used Program $\mathrm{R}^{42}$, package 'lme4', and generalized linear and mixed effects logistic regression models to test whether females chose mates with above average heterozygosity and to predict pup survival as a function of mated pair heterozygosity. To model female mate choice, I used a binary response variable with males of below average heterozygosity ( 0 ) and above average heterozygosity (1) against continuous female heterozygosity values. For pup survival (alive $=1$, dead $=0$ ), I also assessed factors previously found to influence survival of young, chiefly, number of adults in the group, number of years breeders were paired, harvest rate during the previous year (because harvest at time $t$ affects pup survival at $\mathrm{t}+1$ ), and population density (wolves $/ 1000 \mathrm{~km}^{2}$ ). I rescaled independent variables using a $\mathrm{z}$-transformation for ease in comparing the resultant model coefficients. I considered a female's mate choice as a unique event each year. However, because pairs often mate for $>1$ year, I also modeled "mated pair ID" as a random effect using a mixed effects model. P-values for each covariate were estimated using asymptotic Wald tests from package 'lme4' in Program R version 4.0.4 ${ }^{42}$. I used Akaike's Information Criterion (AIC) to compare candidate and null models. Finally, I used a T-test to assess potential differences in heterozygosity between sneaker males and group-living mated males.

Ethics approval. Sampling was conducted under University of Montana IACUC (Animal Use Protocol 008-09MMMCWRU).

\section{Results}

I genotyped 925 individuals in 16 groups and estimated survival for 357 pups from 2008 to 2017. Individuals were detected 1-44 times. Average heterozygosity for all sampled individuals was $0.75(\mathrm{SD}=0.11), 7 \%$ higher than the wolves reintroduced in 1995 and $1996\left(\mathrm{H}_{\mathrm{o}}=0.70^{18}\right)$, albeit using several different loci. Across 83 independent reproduction events, I identified 37 female breeders, 30 male breeders, and 10 additional "sneaker" male breeders who appeared to be unaffiliated with sampled groups. Average breeding female and male observed heterozygosity was $0.74(\mathrm{SD}=0.10)$ and $0.78(\mathrm{SD}=0.12)$, respectively. Average heterozygosity for unsampled, "sneaker" male breeders was $0.65(\mathrm{SD}=0.10)$, significantly lower than mated group-living males $(T=4.13, P=0.0008)$. Across all mated pairs, average heterozygosity was $0.75(\mathrm{SD}=0.07)$.

Females with below average heterozygosity did not choose mates with above average heterozygosity $(\beta=-0.43, \mathrm{SE}=2.63, P=0.87)$. The model predicting female mate choice as a function of male heterozygosity performed poorly compared to a null, intercept only model (+1.97 AIC from null model). Median genetic relatedness between breeders was very low, 0.00 (range 0.00-0.54), although there were five instances (6\%) of wolves breeding with related individuals $(\bar{x}=0.51$, range $0.50-0.54)$ in their group. Mean relatedness of simulated mated pairs was 0.00 assuming random mating in the population.

Pup survival was not higher for mated pairs with above average heterozygosity in either fixed $(\beta=-0.12$, $\mathrm{SE}=0.12, P=0.32$; Table 1$)$ or mixed effects models $(\beta=-0.01, \mathrm{SE}=0.19, P=0.94$; Table 1$)$. The dominant variables predicting pup survival in fixed effects models were harvest rate $(\beta=-0.56, \mathrm{SE}=0.12, P<0.0001)$ and years pairs were mated $(\beta=0.28, \mathrm{SE}=0.13, P=0.04$, Table 1$)$. Only harvest rate was significant in mixed effects models $(\beta=-0.61, \mathrm{SE}=0.14, P<0.0001$, Table 1$)$. The random effect for "pair ID" in the mixed effects model had a $S D=0.85$ and likely captured, in part, the positive effect of years pairs were mated. Both fixed and mixed effects models performed better than a null, intercept only model ( $>-28.0$ AIC from null model), however, a mixed effects model was most supported overall ( -7.3 AIC from fixed effects model). 


\section{Discussion}

I show that genetic diversity remained high in a translocated population of wolves $>20$ years after reintroduction. The mechanism for maintaining such diversity did not appear related to individuals preferentially choosing more genetically diverse mates. I found, however, that wolves generally (94\%) did not mate with family members and appeared to select mates randomly with respect to genetic relatedness. Thus, inbreeding avoidance appears to be at least one mechanism maintaining genetic diversity in this population. Observed heterozygosity $(0.75$; range $0.50-1.00)$ was similar to that reported by Ausband and Waits $\left(2020 ; 0.76^{43}\right)$ for Idaho's wolf population although their estimate did not include the 357 pups that I present here. The observed heterozygosity in Idaho's reintroduced population of wolves was similar to values reported from other recovering wolf populations ${ }^{4-46}$. Roininen et al. ${ }^{45}$ reported observed heterozygosity of 0.68-0.71 for wolves in Finland through 2004, although more recent estimates through 2009 show heterozygosity has declined in the population (0.62) likely due to inbreeding and population isolation ${ }^{44}$.

How is high genetic diversity being maintained in Idaho's wolf population? Some studies have shown that individuals will choose mates with higher average heterozygosity than what is expected if there were random mating in the population ${ }^{13,14}$. I did not observe such mate selection and it does not appear to be a mechanism for conserving genetic diversity in Idaho's wolves. Idaho is part of larger population of wolves encompassing four other western states in the U.S. (Oregon, Washington, Montana, Wyoming) as well as the province of British Columbia in Canada. This larger western North America metapopulation holds $>3000$ wolves ${ }^{47-51}$ and although movement of wolves from some areas into Idaho may be limited and unlikely, we do know wolves frequently disperse long distances crossing state and provincial boundaries in the population ${ }^{41}$. I posit that the high heterozygosity observed in Idaho reflects inbreeding avoidance and dynamics inherent to the larger western North America metapopulation and movement (and subsequent breeding) of wolves into and out of Idaho.

I hypothesized that females would choose mates who were more genetically diverse than average, particularly when the male was not affiliated with the group. Surprisingly, such sneaker males were not as genetically diverse as males who were mated within groups. Reid et al. ${ }^{52}$ found male song sparrows (Melospiza melodia) who were inbred rarely sired extra-pair offspring. While sneaker males in our study had lower heterozygosity than average (0.65), it was not appreciably lower than the heterozygosity of the original reintroduced wolves, albeit using several different $\operatorname{loci}^{18}$. Female wolves enter estrus once per year for a period of just one week $\mathrm{k}^{53}$ and the availability of a potential mate must overlap this period. Females choosing to mate with a male who is unaffiliated with the group may be "making the best of a bad job" by avoiding inbreeding with a related male or infertile partner at the cost of breeding with a sneaker male who may not have optimal genetic diversity. Relatedness between breeding females and sneaker males was $0.07(\mathrm{SD}=0.10)$, slightly higher than what I observed for group-living pairs (0.00). This suggests that sneaker males may be individuals who have dispersed from their natal group and subsequently exist nearby as "floaters" or as members of neighboring groups.

Ultimately, the genetic diversity metric I used was not predictive of wolf pup survival. Harvest and years pairs were mated were influential predictors of pup survival, mirroring previous work conducted on Idaho's wolves $^{54,55}$. Harvest has both direct (i.e., pups are hunted and trapped) and indirect effects on pup survival (i.e., harvest affects group composition thereby reducing pup survival). Additionally, pairs mated for longer periods of time appear to improve their ability to protect and provision young, ultimately leading to higher reproductive rate for such pairs ${ }^{55,56}$.

A lack of genetic diversity can result in lower reproduction and survival and ultimately increase the probability of extinction ${ }^{6,8}$. Although I did not observe Idaho's wolves to be genetically impoverished, large reductions in population size or reduced connectivity with the larger western North America metapopulation could conceivably produce such effects. Rigorous genetic monitoring and tests for associations between diversity and reproduction might be useful in the event of large wolf population reductions.

\section{Data availability}

Data can be found at: https://doi.org/10.5281/zenodo.5764792.

Received: 13 July 2021; Accepted: 16 December 2021

Published online: 11 January 2022

\section{References}

1. Allendorf, F. W., Luikart, G. \& Aitken, S. N. Conservation and the Genetics of Populations (Wiley, 2013).

2. Crnokrak, P. \& Roff, D. Inbreeding depression in the wild. Hered 83, 260-270 (1999).

3. Liberg, O. et al. Severe inbreeding depression in a wild wolf Canis lupus population. Biol. Lett. 1, 17-20 (2005).

4. Frankham, R. Inbreeding in the wild really does matter. Hered 104, 124 (2010).

5. Janicke, T., Vellnow, N., Lamy, T., Chapuis, E. \& David, P. Inbreeding depression of mating behavior and its reproductive consequences in a freshwater snail. Behav. Ecol. 25, 288-299 (2014).

6. Madsen, T., Stille, B. \& Shine, R. Inbreeding depression in an isolated population of adders Vipera berus. Biol. Conserv. 75, 113-118 (1996).

7. Clark, R. W., Marchand, M. N., Clifford, B. J., Stechert, R. \& Stephens, S. Decline of an isolated timber rattlesnake (Crotalus horridus) population: Interactions between climate change, disease, and loss of genetic diversity. Biol. Conserv. 144, 886-891 (2011).

8. Keller, L. F. \& Waller, D. M. Inbreeding effects in wild populations. Trends Ecol. Evol. 17, 230-241 (2002).

9. Slate, J., Kruuk, L. E. B., Marshall, T. C., Pemberton, J. M. \& Clutton-Brock, T. H. Inbreeding depression influences lifetime breeding success in a wild population of red deer (Cervus elaphus). Proc. R. Soc. Lond. B 267, 1657-1662 (2000).

10. Chapman, J. R., Nakagawa, S., Coltman, D. W., Slate, J. \& Sheldon, B. C. A quantitative review of heterozygosity-fitness correlations in animal populations. Mol. Ecol. 18, 2746-2765 (2009).

11. Szulkin, M., Bierne, N. \& David, P. Heterozygosity-fitness correlations: a time for reappraisal. Evolution 64, 1202-1217 (2010).

12. Brown, J. L. A theory of mate choice based on heterozygosity. Behav. Ecol. 8, 60-65 (1997). 
13. Landry, C. D., Garant, D., Duchesne, P. \& Bernatchez, L. 'Good genes as heterozygosity': The major histocompatibility complex and mate choice in Atlantic salmon (Salmo salar). Proc. R. Soc. Lond. B 268, 1279-1285 (2001).

14. Rubenstein, D. R. Female extrapair mate choice in a cooperative breeder: Trading sex for help and increasing offspring heterozygosity. Proc. R. Soc. Lond. B 274, 1895-1903 (2007).

15. Ewen, J. G., Armstrong, D. P., Parker, K. A. \& Seddon, P. J. Reintroduction Biology: Integrating Science and Management (Wiley, 2012).

16. Maehr, D. S. \& Lacy, R. C. Avoiding the lurking pitfalls in Florida Panther recovery. Wild. Soc. Bull. 30, 971-978 (2002).

17. Hedrick, P. W. \& Fredrickson, R. J. Captive breeding and the reintroduction of Mexican and red wolves. Mol. Ecol. 17, 344-350 (2008).

18. vonHoldt, B. M. et al. A novel assessment of population structure and gene flow in grey wolf populations of the Northern Rocky Mountains of the United States. Mol. Ecol. 19, 4412-4427 (2010).

19. Bangs, E. E. \& Fritts, S. H. Reintroducing the gray wolf to central Idaho and Yellowstone National Park. Wild. Soc. Bull. 24, 402-413 (1996).

20. Ausband, D. E. Multiple breeding individuals within groups in a social carnivore. J. Mamm. 99, 834-836 (2018).

21. Western Regional Climate Center. Historical Climate Information. http://www.wrcc.dri.edu. Accessed 20 Aug 2018.

22. Ausband, D. E. Gray wolf harvest in Idaho. Wild Soc. Bull. 40, 500-505 (2016).

23. Ausband, D. E. et al. Surveying predicted rendezvous sites to monitor gray wolf populations. J. Wild Manag. 74, 1043-1049 (2010).

24. Harrington, F. H. \& Mech, L. D. An analysis of howling response parameters useful for wolf pack censusing. J. Wild. Manage 46, 686-693 (1982).

25. Stenglein, J. L., Waits, L. P., Ausband, D. E., Zager, P. \& Mack, C. M. Efficient noninvasive genetic sampling for monitoring reintroduced wolves. J. Wild. Manage 74, 1050-1058 (2010).

26. Onorato, D., White, C., Zager, P. \& Waits, L. P. Detection of predator presence at elk mortality sites using mtDNA analysis of hair and scat samples. Wild Soc. Bull. 34, 815-820 (2006).

27. Holmes, N. G., Strange, N. J., Binns, M. M., Mellersh, C. S. \& Sampson, J. Three polymorphic canine microsatellites. Anim. Gen. 25, 200 (1994)

28. Breen, M. et al. Chromosome-specific single-locus FISH probes allow anchorage of an 1800-marker integrated radiation-hybrid/ linkage map of the domestic dog genome to all chromosomes. Genom. Res. 11, 1784-1795 (2001).

29. Guyon, R. et al. A 1-Mb resolution radiation hybrid map of the canine genome. Proc. Nat. Acad. Sci. USA 100, 5296-5301 (2003).

30. Salim, D. C. et al. Genetic variability in maned wolf based on heterologous short-tandem repeat markers from domestic dog. Genet. Mol. Res. 6, 348-357 (2007).

31. Ostrander, E. A., Wayne, R. K., Freedman, A. H. \& Davis, B. W. Demographic history, selection and functional diversity of the canine genome. Nat. Rev. Genet. 18, 705-720 (2017).

32. Peakall, R. \& Smouse, P. E. GENALEX 6: Genetic analysis in Excel. Population genetic software for teaching and research. Mol. Ecol. 6, 288-295 (2006).

33. Adams, J. R. \& Waits, L. P. An efficient method for screening faecal DNA genotypes and detecting new individuals and hybrids in the red wolf (Canis rufus) experimental population area. Conserv. Gen. 8, 123-131 (2007).

34. Miller, C. R., Joyce, P. \& Waits, L. P. Assessing allelic dropout and genotype reliability using maximum likelihood. Genetics 160, 357-366 (2002).

35. Stenglein, J. L., Waits, L. P., Ausband, D. E., Zager, P. \& Mack, C. Estimating gray wolf pack size and family relationships using noninvasive genetic sampling at rendezvous sites. J. Mamm. 92, 784-795 (2011).

36. Stenglein, J. L., De Barba, M., Ausband, D. E. \& Waits, L. P. Impacts of sampling location within a faeces on DNA quality in two carnivore species. Mol. Ecol. Res. 10, 109-114 (2010).

37. Stansbury, C. R. et al. A long-term population monitoring approach for a wide-ranging carnivore: Noninvasive genetic sampling of gray wolf rendezvous sites in Idaho, USA. J. Wild. Manag. 78, 1040-1049 (2014).

38. Jones, O. \& Wang, J. COLONY: A program for parentage and sibship inference from multilocus genotype data. Mol. Ecol. Res. 10, 551-555 (2009).

39. Wang, J. COANCESTRY: A program for simulating, estimating and analysing relatedness and inbreeding coefficients. Mol Ecol Res 11, 141-145 (2011).

40. Frasier, T. R. STORM: Software for testing hypotheses of relatedness and mating patterns. Mol. Ecol. Res. 8, 1263-1266 (2008).

41. Jimenez, M. D. et al. Wolf dispersal in the northern Rocky Mountains, western United States: 1993-2008. J. Wild Manag. 81, $581-592(2017)$.

42. R Core Team. (2019). R version 3.6.2 (2019-12-12) "Dark and Stormy Night" Copyright (C) 2019 The R Foundation for Statistical Computing. http://www.R-project.org/

43. Ausband, D. E. \& Waits, L. Does harvest affect genetic diversity in gray wolves?. Mol. Ecol. 29, 3187-3195 (2020).

44. Jansson, E., Ruokonen, M., Kojola, I. \& Aspi, J. Rise and fall of a wolf population: genetic diversity and structure during recovery, rapid expansion and drastic decline. Mol. Ecol. 21, 5178-5193 (2012).

45. Roininen, J. A., Ruokonen, M., Kojola, I. \& Vila, C. Genetic diversity, population structure, effective population size and demographic history of the Finnish wolf population. Mol. Ecol. 15, 1561-1576 (2006).

46. Korablev, M. P., Korablev, N. P. \& Korablev, P. N. Genetic diversity and population structure of the grey wolf (Canis lupus Linnaeus, 1758) and evidence of wolf $\times$ dog hybridisation in the centre of European Russia. Mamm. Biol. 101, 91-104 (2021).

47. Inman, B., et al. (2019) Montana Gray Wolf Conservation and Management 2019 Annual Report. Montana Fish, Wildlife \& Parks, Helena.

48. IDFG [Idaho Department of Fish and Game]. Idaho Wolf Populations Remains Stable Between 2019 and 2020 Despite Higher Mortality. Roger Phillips, Public Information Supervisor. https://idfg.idaho.gov/press/idaho-wolf-populations-remains-stable-betwe en-2019-and-2020-despite-higher-mortality. Accessed 25 June 2021.

49. ODFW [Oregon Department of Fish and Wildlife]. Oregon Wolf Conservation and Management 2020 Annual Report. Oregon Department of Fish and Wildlife.

50. WDFW [Washington Department of Fish and Wildlife], Confederated Tribes of the Colville Reservation, Spokane Tribe of Indians, USDA-APHIS Wildlife Services, and U.S. Fish and Wildlife Service. Washington Gray Wolf Conservation and Management 2020 Annual Report. Washington Department of Fish and Wildlife (2021).

51. WGFD [Wyoming Game and Fish Department\}, U.S. Fish and Wildlife Service, National Park Service, USDA-APHIS-Wildlife Services, and Eastern Shoshone and Northern Arapahoe Tribal Fish and Game Department. Wyoming Gray Wolf Monitoring and Management 2020 Annual Report. Wyoming Game and Fish Department (2021).

52. Reid, J. M., Arcese, P., Sardell, R. J. \& Keller, L. F. Additive genetic variance, heritability, and inbreeding depression in male extrapair reproductive success. Am. Nat. 177, 177-187 (2011).

53. Asa, C. A., Seal, U. S., Plotka, E. D., Letellier, M. A. \& Mech, L. D. Effect of anosmia on reproduction in male and female wolves (Canis lupus). Behaav. Neurol. Biol. 46, 272-284 (1986).

54. Ausband, D. E., Stansbury, C., Stenglein, J. L., Struthers, J. L. \& Waits, L. P. Recruitment in a social carnivore before and after harvest. Anim. Conserv. 18, 415-423 (2015).

55. Ausband, D. E. Pair bonds, reproductive success, and rise of alternate mating strategies in a social carnivore. Behav. Ecol. 30, 1618-1623 (2019). 
56. Bradley, J. S., Wooller, R. D. \& Skira, I. J. The relationship of pair-bond formation and duration to reproductive success in shorttailed shearwaters Puffinus tenuirostris. J. Anim. Ecol. 64, 31-38 (1995).

\section{Acknowledgements}

I thank M. A. Hurley, J. S. Husseman, J. Krohner, M. S. Mitchell, S. B. Roberts, C. R. Stansbury, J. L. Stenglein, J. L. Struthers, J. Adams, and L. Waits for their assistance. I also thank seasonal technicians for their hard work and diligence in the field. Any use of trade, firm, or product names is for descriptive purposes only and does not imply endorsement by the U.S. Government. This paper was subject to U.S. Geological Survey's Fundamental Science Practices (https://pubs.usgs.gov/circ/1367).

\section{Author contributions}

D.A. designed and implemented the study, analyzed the data, and wrote the manuscript.

\section{Funding}

Regina Bauer Frankenberg Foundation for Animal Welfare, Bernice Barbour Foundation, Coypu Foundation, Eppley Foundation for Research, Idaho Department of Fish and Game, Kampe Foundation, Leonard X. Bosack and Bette M. Kruger Charitable Foundation, Nancy Carroll Draper Foundation, Nez Perce Tribe, Oregon Zoo Future for Wildlife grants, Shikar Safari Club International Foundation, Steven Leuthold Family Foundation, The Mountaineers Foundation, U.S. Fish and Wildlife Service, U.S. Geological Survey, Wilburforce Foundation, Wolf Recovery Foundation, University of Idaho College of Natural Resources, and University of Idaho Environmental Science Program.

\section{Competing interests}

The author declares no competing interests.

\section{Additional information}

Correspondence and requests for materials should be addressed to D.E.A.

Reprints and permissions information is available at www.nature.com/reprints.

Publisher's note Springer Nature remains neutral with regard to jurisdictional claims in published maps and institutional affiliations.

Open Access This article is licensed under a Creative Commons Attribution 4.0 International License, which permits use, sharing, adaptation, distribution and reproduction in any medium or format, as long as you give appropriate credit to the original author(s) and the source, provide a link to the Creative Commons licence, and indicate if changes were made. The images or other third party material in this article are included in the article's Creative Commons licence, unless indicated otherwise in a credit line to the material. If material is not included in the article's Creative Commons licence and your intended use is not permitted by statutory regulation or exceeds the permitted use, you will need to obtain permission directly from the copyright holder. To view a copy of this licence, visit http://creativecommons.org/licenses/by/4.0/.

This is a U.S. Government work and not under copyright protection in the US; foreign copyright protection may apply 2022 